\title{
There is nothing to fear but the amygdala: applying advances in the neuropsychiatry of fear to public policy
}

\author{
Lawrence Amsel • Spencer Harbo • \\ Amitai Halberstam
}

Received: 24 October 2013/Accepted: 9 July 2014/Published online: 30 September 2014

(C) The Author(s) 2014. This article is published with open access at Springerlink.com

\begin{abstract}
The last 25 years have seen advances in our understanding of the neuroscience and neuropsychiatry of fear. From the basic brain mechanisms of fear to new evidence-based treatments for the pathologies of fear, the field has experienced progress towards an understanding of the underpinnings of fear in the brain and its influence on behaviors. Yet, to date, there has been less than ideal incorporation of these new findings, insights and models into the public policy and economic domains. Even when notions of risk, uncertainty, and emotional decision-making are discussed, these discussions may not access insights from the latest contemporary neuroscience of fear, or clinical techniques in changing pathological fear responses. This paper will explore how a more complete incorporation of these advances may contribute to our understanding of fear and its management. Applying these advances in specific amenable policy areas may lead to new, more effective approaches to public and economic policies.
\end{abstract}

L. Amsel ( $ه)$

Department of Psychiatry, Columbia University, 245 West 107th Street,

New York, NY 10025, USA

e-mail: Lamse101@gmail.com

S. Harbo

School of Natural Resources and Environment, University of Michigan, 440 Church Street, Ann Arbor, MI 48109, USA

e-mail: spencerharbo@gmail.com

\section{A. Halberstam}

Bard College Berlin, Berlin, Germany

Present Address:

A. Halberstam

300 Riverside Drive, New York, NY 10025, USA 
Keywords Fear - Emotion · Neuropsychiatry $\cdot$ Amygdala $\cdot$ Economics $\cdot$ Public policy

\section{Introduction}

Fear and threat-elicited defense responses, whether or not consciously perceived, influence human behavior at both the individual and societal level. In the globalized economy of the twenty first Century, these phenomena may manifest themselves in policies that affect the lives of billions of people. Yet, the biological origins of fear and defense responses and their effect on decision-making may not be well understood by policy makers. Moreover, the response to threat and the experience of fear may interact with the cognitive tasks involved in risk assessment in complicated ways that have not yet been fully explored.

Through these interactions, fear may be among the most powerful phenomena guiding current economic and public policy, and yet its influence may go unacknowledged. Two factors have been responsible for this lack of understanding. On the one hand, from an empirical psychological perspective, there has only recently been a significant improvement in our knowledge concerning the biological underpinnings of fear and threat response and their potential impact on behavior. On the other hand, fear and other emotions have often been excluded from rationalist economic and public policy discourse. They were seen as non-rational and thus at best non-commensurable with rationalist models, and at worst as pathological barriers to good decision-making. Fortunately, the last several decades have seen increased attention to the empirical study of fear within the disciplines of neuroscience (e.g., LeDoux 1998, 2000), behavioral psychology (e.g., Marshall et al. 2007), and psychiatry (e.g., Schneier et al. 2012), as well as a greater acceptance within economics of the appropriate role of emotions, including fear, in models of decision-making (e.g., Bell 1981; Pope 2009).

One of the difficulties of incorporating fear into our economic and public policy models is the multiplicity of definitions and conceptualizations of fear and its close relative, anxiety. For example, fear had often been thought of primarily as a conscious phenomenon that takes place within human awareness. However, with recent advances in neuroscience, researchers now conceptualize automatic behavioral responses to threat that bypass conscious thought processes (e.g., freezing, motor withdrawal) as part of the fear network (Ohman and Mineka 2001). However, as the precise brain mechanisms of these phenomena differ (LeDoux 2012), a distinction is called for. LeDoux (2013) suggests a separation of terms to define conscious, emotional states of 'fear' and the automatic 'threat-elicited defense responses.' We attempt to take the same approach here, distinguishing between the conscious state of fear and automatic defense responses, which may both be products of the brain's threat-avoidance network, but are causally and representationally distinct (Mobbs et al. 2009).

We are gradually learning to sort out those aspects of fear that are amenable to rational cognitive or computational modeling, from those that involve so-called 
emotional responses, which are an alternative mode of processing fear information. Some of these responses may involve somatic sensations, as described by Demasio in his Somatic Marker Hypothesis (Demasio et al. 1991), and may give rise to more dichotomous judgments that are inconsistent with more rational probability matching. Note, this processing mode is more consistent with the notion of fear as a response mechanism in a hostile world, rather than as a risk evaluation process, useful in a system seeking to maximize benefit.

The recent advances in understanding fear in the human brain, though still tentative, may give rise to a new approach to this complex phenomenon, that has significant implications for economic and public policies. This paper will next briefly introduce some of the foundations of the new approach to fear and threat response in order to highlight its potential impact on future policy decisions.

\subsection{The complex nature of fear}

Although humans have a strong belief, based on conscious experience, that our mind (and therefore our brain) functions as a unitary entity working towards a single goal, there is growing evidence from neuroscience that there are many systems in the brain acting independently and even in competition with one another (Han et al. 2007; Kelly et al. 2008; Peters et al. 2004; Poldrack and Packard 2003). While the more primitive parts of the brain like the amygdala focus on automatic responses such as threat detection, advanced structures like the prefrontal cortex focus on cognitive control and decision-making. There are also specific brain circuits that work to resolve conflicts in a context-specific manner (Egner and Hirsch 2005; Egner et al. 2008; Etkin et al. 2006), whether the conflict lies in the stimuli being processed or the internal response to those stimuli (Egner et al. 2007). In light of these findings, the brain can be seen as a complex economy, consisting of many agents that may be pursuing divergent goals, but nonetheless need to interact with each other.

The complex nature of the brain can be easily observed in the context of fear and threat response, as they can be experienced in several fundamentally different ways depending on the context and specific stimulus of threat (LeDoux 2012; Mobbs et al. 2009; Ponnusamy et al. 2007). There are mechanisms of fear that occur in response to external stimuli, both within and outside of awareness, that can in turn produce autonomic, automatic, or voluntary behavioral responses, some of which focus on the goal of avoiding danger (Ohman and Mineka 2001), while others may be assimilating information for future use. Fear can also be experienced without a stimulus as a conscious emotional state, e.g., fear of potential future events such as terrorism or environmental catastrophe, or fear related to memories of past traumatic events. Moreover, fear sometimes becomes self-referential, wherein the state of fear itself becomes something to fear, an aversive condition that is avoided as much as the external stimulus that initially caused the fear, leading to thought blocking, denial, and avoidance behaviors (Chambless and Gracely 1989).

Mobbs et al. (2009) have observed that the higher brain regions process more abstract fear, while midbrain regions respond to imminent threat. The primitive threat response that occurs as a survival-based defense mechanism has an internal 
logic that is black-and-white and inflexible, while the conscious fear generated by deliberate reasoning is dynamic and depends on contextual factors, anticipated future conditions, emotions and memories. These separate systems of fear may act independently and their interaction can be synergistic, or potentially counterproductive. For instance, the response towards specific stimuli, e.g., snakes, can be useful for avoiding danger, but avoidance behaviors that become generalized, e.g., avoiding wooded areas for fear of encountering a snake, may prevent action and is therefore detrimental to the system as a whole. This dichotomy can be understood from an evolutionary perspective, as the human brain was not planned in advance, but rather evolved from pre-existing systems.

\subsection{The evolution of fear}

Human cognition and behavior have evolved over time in tandem with changes to the structural composition and neurocircuitry of the brain. The evolution of the human brain has involved the preservation of primitive brain structures and their associated processes, while developing new structures and processes on top of these. Thus, the prefrontal cortex, which contributes to higher-level critical thinking and decision-making, literally sits atop more 'primitive' mid-brain regions and communicates with them.

From the context of survival, the fear systems serve the purpose of identifying and attending to threats, initiating a defense response (fight-or-flight), and preparing an individual for the appropriate action that will preserve life (Perna 2013). As an example, a fear of snakes has evolved in humans and other primates as a survival mechanism, which is still active in many individuals (Ohman and Mineka 2003). While logic and critical thinking may be useful in planning for the future and improving general conditions of life, the autonomic (nervous system) and automatic (motor) products of threat response serve the vital purpose of shielding us from potential harm or death and favor immediate survival over long-term thriving.

The capacity for conscious states of fear and the consolidation of fear memories may have developed in humans to help us better respond to repeated threats and plan for future danger. In some cases fear memories may lead to pathologies of fear and exaggerated caution (discussed below). Understanding the biological and evolutionary bases of fear, both in its helpful and destructive aspects, may help policymakers better anticipate reactions to catastrophic events in the future, while better preparing society to face risk and uncertainty.

\subsection{The current neuroscience of fear}

The current neuroscience perspective indicates that the brain regions involved in threat response and fear are not organized into a single fear circuit (LeDoux 2012). Rather, threat-related stimuli are processed by several circuits in parallel. These simultaneous streams of processing can help us understand the internal inconsistencies inherent in human fear and threat response. Here an example from the clinic may help. It is not uncommon for First Responders exposed to a particularly intense trauma to become avoidant of elements of the trauma as a result of fear 
conditioning, for example, tunnels, subways, or even elevators. If asked about the probabilities of danger from these circumstances, these individuals are able to give good estimates of the low probability of danger, but behaviorally they act as if their probability estimates were very high, or as if there were a binary threat detection labeling some things as completely dangerous and others as safe, without the nuance of probability. Such inconsistencies have been the source of the impression that the fear can be irrational, as it is not even internally consistent.

Multiple lines of research within neuroscience (broadly defined here as the study of brain and nervous tissue by the observational methods of biological science) point to a set of brain regions organized into a set of circuits that underlie our complex response to threat. In a somewhat simplified model, the major regions include: the sensory cortex (stimulus awareness), hippocampus (memory of associated stimuli), amygdala (rapid evaluation of danger potential), bed nucleus of stria terminalis (relay of fear-related signal), prefrontal cortex (integration and conscious decision-making), and hypothalamus (release of stress hormones) (Sah and Westbrook 2008). Of these, the key structure now believed to be governing fear is the amygdala, which plays a central role in both automatic threat response and conscious fear processing (Davis 1992; LeDoux 2003; Rosen and Donley 2006; Shin and Liberzon 2010).

Evidence for this central role comes from several convergent neuroscience approaches. Classical conditioning experiments have been used to demonstrate the role of the amygdala in fear learning and unlearning (extinction) (Davis 1992; Knight et al. 2004; LeDoux et al. 1990; Phillips and LeDoux 1992; Sotres-Bayon et al. 2006; Rogan et al. 1997). Functional MRI studies, while tentative and based on small samples, further suggest that the amygdala's role in processing emotions is focused on fear. For example, increased activity within the amygdala has been observed when a person is presented with angry and fearful faces, but not happy or neutral ones (Breiter et al. 1996; Mattavelli et al. 2013). Moreover, damage to the amygdala has been shown to interfere with the conditioning of fear responses (LeBar et al. 1995; LeDoux et al. 1988) and cause deficits to the processing of negative emotions, such as fear (Adolphs et al. 1995; Sprengelmeyer et al. 1999; Tranel et al. 2006).

Moreover, the amygdala participates in fear learning and memory formation (LeBar et al. 1998; LeDoux 1998; Rogan et al. 1997), so that particular events may have a fear "label" attached as they are filed in our memory banks, a process known as fear consolidation (LeDoux 2007). Heightened amygdala activity has also been observed in posttraumatic stress disorder (PTSD), specific phobias, and generalized anxiety disorder (Shin and Liberzon 2010). It is important to note, however, that the amygdala is not always involved in fear processing and response. For instance, it seems not to be involved when when reacting to a specific already frequently encountered threat (Ponnusamy et al. 2007).

\subsection{Fear learning and pathologies of fear}

Behavioral and FMRI studies have been instrumental in shedding light on the mechanisms of fear learning and the origins of fear-related pathologies, specifically 
how fear is spread from a dangerous stimulus to a neutral one, a property known as conditioning. Much of the research on fear and its mechanisms in the brain has focused on experiments that employ classical conditioning, modeled after Pavlov's (1927) initial experiments. Classical conditioning models, when applied to fear, are known as fear learning models and operate through the association of a fear response to a conditioned, innocuous stimulus. Common fear responses elicited by a conditioned stimulus, such as a bell that rings just before an electric shock, include increased heart rate, release of hormones, and freezing (LeDoux 2000). It is important to note that while the association of conditioned stimuli with a threat responses is learned, the responses themselves are not learned but are pre-existing, species-specific responses to danger (LeDoux 1998).

Fear conditioning has been shown to alter the amygdala's response to threat in the same way as the induction of long-term potentiation, an experience-dependent form of neuroplasticity involved in memory formation (Rogan et al. 1997). Unlike other memories however, fear memories may elicit more than just a fear response and may actually re-ignite the whole negative experience of the original dangerous event. For example, in response to a small cue, individuals with PTSD may experience physiological reactions (increased heart rate, trouble breathing, or sweating), but may also experience a whole re-experiencing of the traumatic event (American Psychiatric Association 2013). This may be the result of the focusing of attention towards fearful aspects of a situation or the selective clarity of fear memory. Both the focusing and the memory may help an individual more efficiently avoid future threats. But the avoidance of future dangers may come at a cost to individuals suffering from pathologies of fear.

Similar to other types of emotional and behavioral conditioning, fear conditioning is initially context specific, but can generalize through over-learning to include a wide variety of stimuli that do not pose any significant danger. For example, people in a car accident may first learn to fear cars, but this may generalize to a fear of any mode of transportation. In this way fear can lead to a more general state of anxiety, resulting in detrimental avoidance behaviors. Fear-based anxiety disorders, such as panic disorder, phobias, and PTSD, affect a large percentage of the population, estimated at $28.8 \%$ in the United States (Kessler et al. 2005). Such fear-related pathologies can arise from contextual factors (Marshall et al. 2007) or from individual traits, as some persons may be more susceptible to developing fearrelated disorders than others (Amstadter et al. 2009; Kendler et al. 2001).

Pathologies of fear may be the result of increased fear learning through reconsolidation, which leads to enhanced retention of fear memories and a resistance to unlearning the fear (Blechert et al. 2007; Davis 1992; Myers and Davis 2007; Rothbaum and Davis 2003; Sotres-Bayon et al. 2006). In healthy individuals, the behavioral and autonomic responses to once-feared stimuli or past trauma diminish naturally over time, a naturally occurring form of extinction. Similar to fear learning, extinction occurs not through the forgetting of fear, but the overriding of fear memories (Bouton 2004). The parts of the brain identified in the encoding and expression of fear extinction are similar to those identified in fear learning, indicating that fear extinction is a process of "over-learning" - the new interpretation overrides but does not eliminate the earlier interpretations of stimuli as 
threatening. The parts of the brain identified in this process include cortical and subcortical brain areas, especially the interaction between the medial prefrontal cortex, amygdala, and hippocampus (Sotres-Bayon et al. 2006).

In individuals who develop fear-related pathologies such as PTSD, the extinction of the fear memory may be inhibited, resulting in persistent symptoms such as reexperiencing a traumatic event (Rothbaum and Davis 2003). Advances in our understanding of fear learning and extinction mechanisms in the brain have implications for the treatment of fear-based pathologies through structured programs of fear extinction (Garakani et al. 2006). Exposure therapy, which aids the reduction of fear memories by reintroducing a conditioned fear stimulus in a safe context, has been used as an effective treatment to alleviate those suffering from persistent fear memories (Adenauer et al. 2011; Dias et al. 2013; Rothbaum and Schwartz 2002; Schneier et al. 2012). This can also occur without formal therapy (Davis et al. 2005; Hauner et al. 2013), and therefore this process can be applied widely.

The treatment methods described above have implications for individuals and society, as deficits caused by fear conditioning can also impact larger groups. Collective trauma can be experienced by those outside the spatial proximity of a traumatic event, manifesting in anxiety, PTSD symptoms, and increased substance use (Marshall and Galea 2004; Marshall et al. 2007). This can occur through media exposure, especially among children (Custers and Van den Bulck 2012). The emotion of fear has even been observed to override positive emotions, like hope, in societies exposed to years of conflict (Bar-Tal 2001). This is not surprising, given our current understanding of fear consolidation and memory formation. In order to improve the response to mass traumatic events, like terror attacks or economic depression, policy makers should pay attention to images and information contributing to fear memories, as these fears may generalize and lead to disruptions to normal behavior and the avoidance of healthy risk taking.

At the same time, increasing awareness of potential threats may also be beneficial, as mental health at individual and societal levels may be dependent on the correct mix of hope and fear (Pope 2009). With the absence of appropriate fear individuals may be inadequately prepared for future disasters. As learned responses to threat have been shown to circumvent certain fear circuits in the brain (Ponnusamy et al. 2007). The purposeful introduction of fearful cues when the severity of a potential threat cannot be detected, may help. This approach has been effectively used by government agencies that place graphic warnings on cigarette packs to prevent smoking, and could be used similarly to promote other healthy behaviors (Field 2013). Thus, building on our current understanding of fear learning and extinction is important for addressing issues of public policy that may influence or be influenced by individual or societal fear.

\subsection{Risk taking and fear}

Risk assessment is an important decision-making process that has implications for both survival and wellbeing. Animal studies show that risk taking is influenced by a multitude of factors (Stankowich and Blumstein 2005), and obviously many more 
factors may influence risk-taking behaviors in humans (Marshall et al. 2007). Risk taking has an evolutionary basis (Ellis et al. 2012) and may be dependent on the interaction between logical reasoning and psychosocial factors in the brain (Steinberg 2007). For instance, Slovic and Peters (2006) describe dichotomous states of experiencing risk as a feeling and perceiving risk analytically using logic and computation. The reasoned ways of perceiving risk can be interpreted as a step in decision making process whereby the possible outcomes of a threat or stressor are formulated and the appropriate action is taken (Pope 2009).

Recent advances in the neuroscience of fear, on the one hand, and the behavioral turn in economics, on the other, have resulted in an increase of interest in the role of fear on risk-taking. Risk assessment may be unduly influenced by a fear of negative outcomes produced by the threat-detecting processes of the fear networks in the brain (Camerer et al. 2005). At the same time, there may often be a conflict between fear and constructive risk-taking behaviors, which could be explained by the divergent goals of different brain circuits. For example, the risk-taking behaviors of adolescents can be beneficial to society, such as military heroism or the romantic drive, may be carried out despite the mechanisms of fear, that would normally inhibit such behavior.

However, in many cases fear may deter risk-taking behavior. This can occur either directly, through the anticipation of an unpleasant outcome that causes a person to choose a safer option, or indirectly by causing the person to put extreme weight on the probability of the negative outcome (Pope 1995). In putting more weight on a negative outcome than is appropriate for its likelihood of occurrence, one may be deterred from risk taking.

Such caution may be driven by fear circuits that have been recently identified (Tom et al. 2007). On whether it is reasonable to be cautious in this sense, Keynes (1921) notes that it is unclear who will profit more the cautious or the risk-taker. In their early work, Kahneman and Tversky (1979) classify people who put more weight on bad outcomes than their probability of occurring as irrational, whereas Allais 1979 argues it is reasonable to put more weight on bad outcomes. Caution can also arise from loss aversion, that is from people taking their current situation as an overvalued reference point, and putting more weight on future possible losses than on future possible gains. Kahneman (2003, p. 1457) later work can thus be interpreted as saying that taking a reference point, as in loss aversion, is not invariably irrational. However, these models may not focus sufficiently on the period when fear would be most experienced, namely in the pre-outcome period (Pope 1983).

Potential negative outcomes or losses may be more prominent in the decisionmaking process when a threat is felt at the individual level (Bohm and Pfister 2008), and may often be ignored completely by those who have never themselves faced that loss, even where the losses may be horrific as in the case of natural disasters like floods (Kunreuther 1984). However, spatial or temporal proximity to prior event are not the only determinants of risk-taking behavior. Many other factors may influence individuals' decision making in response to perceived risk, contributing to their 'relative risk appraisal' (Marshall et al. 2007). Media coverage, statements by government officials, or other aspects of the cultural milieu may lead people to have 
an exaggerated fear or perception of risk related to a potential threat, thus deterring them from risk-taking behaviors (Fischhoff et al. 1978).

Caution is not necessarily bad; in some environments, it enhances goals and assists in survival. However, when caution is excessive and becomes pathological, neuroscience's recent discoveries may assist in its reversal. Conversely, advances in neuroscience and our understanding of fear conditioning networks may help to balance risk taking in the face of extreme threat, when taking a cautious approach may lead to a better outcome. Thus, given the complex nature of fear and its multiple instantiations, policymakers need to be able to identify what kind of fear is being activated in order to be able to adequately respond to the related changes in group behavior (e.g., economic), and this is especially true in times of crisis and subsequent periods of recovery.

\section{Conclusion}

Any complete theory of fear must take into account that it is a complex phenomenon, a give-and-take between conscious cognitive process and automatic (out-of-awareness) brain functions. Recent advances in neuroscience have been able to show the many ways that the brain processes fear. These findings have helped to shed light on how humans respond to threat, consolidate fear memories, and assess risk, all of which may impact the larger society.

Our ability to improve future policies may depend on incorporating the multiple mechanisms of fear and threat response occurring together in the brain. The advances in what we know about fear suggest that its deterrence of risk taking is sometimes beneficial, sometimes harmful. Recent discoveries of the brain mechanisms behind threat response and risk perception, combined with an improved understanding of fear pathologies and techniques for promoting extinction of fear memories, can aid in formulating public policy for mitigating excessive individual and group fears in some cases and for creating a healthy threat response and perception of risk in others.

Open Access This article is distributed under the terms of the Creative Commons Attribution License which permits any use, distribution, and reproduction in any medium, provided the original author(s) and the source are credited.

\section{References}

Adenauer H, Catani C, Gola H, Keil J, Ruf M, Schauer M, et al (2011) Narrative exposure therapy for PTSD increases top-down processing of aversive stimuli-evidence from a randomized controlled treatment trial. BMC Neurosci 12:127. doi:10.1186/1471-2202-12-127

Adolphs R, Tranel D, Damasio H, Damasio AR (1995) Fear and the human amygdala. J Neurosci 15:5879-5891

Allais M (1979) The so-called Allais paradox and rational decisions under uncertainty. In: Allais M, Hagen $\mathrm{O}$ (eds) Expected utility hypotheses and the Allais paradox: contemporary discussions of decisions under uncertainty with Allais' rejoinder. Reidel, Dordrecht, pp 437-681

American Psychiatric Association (2013) Diagnostic and statistical manual of mental disorders, 5th edn. American Psychiatric Publishing, Arlington 
Amstadter AB, Nuget NR, Koenen KC (2009) Genetics of PTSD: fear conditioning as a model for future research. Psychiatr Ann 39:358-367

Bar-Tal D (2001) Why does fear override hope in societies engulfed by intractable conflict, as it does in the Israeli society? Political Psychol 22:601-627

Bell DE (1981) Components of risk aversion. In: Brans J (ed) Operational research. North Holland, Amsterdam, pp 235-242

Blechert J, Michael T, Vriends N, Margraf J, Wilhelm FH (2007) Fear conditioning in posttraumatic stress disorder: evidence for delayed extinction of autonomic, experiential, and behavioural responses. Behav Res Ther 45:2019-2033

Bohm G, Pfister H (2008) Anticipated and experienced emotions in environmental risk perception. Judgement Decis Mak 3:73-86

Bouton ME (2004) Context and behavioral processes in extinction. Learn Mem 11:485-494

Breiter HC, Etcoff NL, Whalen PJ, Kennedy WA, Rauch SL, Buckner RL et al (1996) Response and habituation of the human amygdala during visual processing of facial expression. Neuron 17:875-887

Camerer C, Loewenstein G, Prelec D (2005) Neuroeconomics: how neuroeconomics can inform economics. J Econ Lit 43:9-64

Chambless DL, Gracely EJ (1989) Fear of fear and the anxiety disorders. Cogn Ther Res 13:9-20

Custers K, Van den Bulck J (2012) Fear effects by the media. Eur J Pediatr 171:613-616

Davis M (1992) The role of the amygdala in fear and anxiety. Annu Rev Neurosci 15:375

Davis M, Myers KM, Ressler KJ, Rothbaum BO (2005) Facilitation of extinction of conditioned fear by D-Cycloserine: implications for psychotherapy. Curr Dir Psychol 14:214-219

Demasio AR, Tranel D, Demasio HC (1991) Somatic markers and the guidance of behavior: theory and preliminary testing. In: Levin HS, Eisenberg HM, Benton AL (Eds) Frontal lobe function and dysfunction. Oxford University Press, 217-229

Dias BG, Banerjee SB, Goodman JV, Ressler KJ (2013) Towards new approaches to disorders of fear and anxiety. Curr Opin Neurobiol 23:346-352

Egner T, Hirsch J (2005) Cognitive control mechanisms resolve conflict through cortical amplification of task-relevant information. Nat Neurosci 8:1790

Egner T, Delano M, Hirsch J (2007) Separate conflict-specific cognitive control mechanisms in the human brain. Neuroimage 35:940-948

Egner T, Etkin A, Gale S, Hirsch J (2008) Dissociable neural systems resolve conflict from emotional versus nonemotional distracters. Cereb Cortex 18:1475-1484

Ellis BJ, Del Giudice M, Dishion TJ, Figueredo AJ, Gray P, Griskevicius V et al (2012) The evolutionary basis of risky adolescent behavior: implications for science, policy, and practice. Dev Psychol 48:598-623

Etkin A, Egner T, Peraza DM, Kandel ER, Hirsch J (2006) Resolving emotional conflict: a role for the rostral anterior cingulate cortex in modulating activity in the amygdale. Neuron 51:871-882

Field RI (2013) What you see is what you fear. Hum Vaccin Immunother 9(12):2670-2671

Fischhoff B, Slovic P, Lichtenstein S, Read S, Combs B (1978) How safe is safe enough? a psychometric study of attitudes towards technological risks and benefits. Policy Sci 9:127-152

Garakani A, Mathew SJ, Charney DS (2006) Neurobiology of anxiety disorders and implications for treatment. Mt Sinai J Med 73:941-949

Han J, Kushner SA, Yiu AP, Cole CJ, Matynia A, Brown RA et al (2007) Neuronal competition and selection during memory formation. Science 316:457-460

Hauner KK, Howard JD, Zelano C, Gottfried JA (2013) Stimulus-specific enhancement of fear extinction during slow-wave sleep. Nat Neurosci 22(11):1553-1555

Kahneman D (2003) Maps of bounded rationality: a perspective on intuitive judgment and choice. In T. Frangsmyr (Nobel Foundation), (Ed.), Les Prix Nobel: The Nobel Prizes 2002 (pp. 449-489). Stockholm SE: The Nobel Foundation, reproduced in Kahneman D (2003) Maps of bounded rationality: psychology for behavioral economics, Am Econ Rev 93 (5), 1449-1475

Kahneman D, Tversky A (1979) Prospect theory: an analysis of decision under risk. Econometrica 47:263

Kelly AM, Uddin LQ, Biswal BB, Castellanos FX, Milham MP (2008) Competition between functional brain networks mediates behavioral variability. Neuroimage 39:527-537

Kendler KS, Myers J, Prescott CA, Neale MC (2001) The genetic epidemiology of irrational fears and phobias in men. Arch Gen Psychiatry 58:257-265 
Kessler RC, Berglund P, Demler M, Jin R, Merikangas KR, Walters EE (2005) Lifetime prevalence and age-of-onset distributions of DSM-IV disorders in the National Comorbidity Survey Replication. Arch Gen Psychiatry 62:593-602

Keynes JM (1921) A treatise on probability. Macmillian and Co., London

Knight DC, Smith CN, Cheng DT, Stein EA, Helmstetter FJ (2004) Amygdala and hippocampal activity during acquisition and extinction of human fear conditioning. Cogn Affect Behav Neurosci 4:317-325

Kunreuther H (1984) Causes of underinsurance against natural disasters. Geneva Pap Risk Insu 9(31):206-220

LeBar KS, LeDoux JE, Spencer DD, Phelps EA (1995) Impaired fear conditioning following unilateral temporal lobectomy in humans. J Neurosci 15:6846-6855

LeBar KS, Gatenby JC, Gore JC, LeDoux JE, Phelps EA (1998) Human amygdala activation during conditioned fear acquisition and extinction: a mixed-trial fMRI study. Neuron 20:937-945

LeDoux J (1998) Fear and the brain: where have we been, and where are we going? Biol Psychiatry 44:1229-1238

LeDoux JE (2000) Emotion circuits in the brain. Annu Rev Neurosci 23:155-184

LeDoux JE (2003) The emotional brain, fear, and the amygdala. Cell Mol Neurobiol 23:727-738

LeDoux JE (2007) The amygdala. Curr Biol 17(20):R868-R874. doi:10.1016/j.cub.2007.08.005

LeDoux J (2012) Rethinking the emotional brain. Neuron 73:653-676

LeDoux JE (2013) The slippery slope of fear. Trends Cogn Sci 17:155-156

LeDoux JE, Iwata J, Cicchetti P, Reis DJ (1988) Different projections of the central amygdaloid nucleus mediate autonomic and behavioral correlates of conditioned fear. J Neurosci 8:2517-2529

LeDoux JE, Cicchetti P, Xagoraris A, Romanski LM (1990) The lateral amygdaloid nucleus: sensory interface of the amygdala in fear conditioning. J Neurosci 10:1062-1069

Marshall RD, Galea S (2004) Science for the community: assessing mental health after 9/11. J Clin Psychiatry 65:37-43

Marshall RD, Bryant RA, Amsel L, Suh EJ, Cook JM (2007) The psychology of ongoing threat: relative risk appraisal, the Septebmer 11 attacks, and terrorism-related fears. Am Psychol 62:304-316

Mattavelli G, Sormaz M, Flack T, Ashgar AUR, Fan S, Frey J et al (2013) Neural responses to facial expressions support the role of the amygdala in processing threat. Soc Cogn Affect Neurosci. doi:10. 1093/scan/nst162

Mobbs D, Marchant JL, Hassabis D, Seymour B, Tan G, Gray M, Petrovic P, Dolan RJ, Frith CD (2009) From threat to fear: the neural organization of defensive fear in humans. $J$ Neurosci 29(39):12236-12243

Myers KM, Davis M (2007) Mechanisms of fear extinction. Mol Psychiatry 12:120-150

Ohman A, Mineka S (2001) Fears, phobias, and preparedness: toward an evolved module of fear and fear learning. Psychol Rev 108:483-522

Ohman A, Mineka S (2003) The malicious serpent: snakes as a prototypical stimulus for an evolved module of fear. Curr Dir Psychol 12:5-9

Pavlov IP (1927) Conditioned reflexes. Dover Publications Inc, New York

Perna G (2013) Understanding anxiety disorders: the psychology and the psychopathology of defence mechanisms against threats. Riv Psichiatr 48:73-75

Peters A, Schweiger U, Pellerin L, Hubold C, Oltmanns KM, Conrad M et al (2004) The selfish brain: competition for energy resources. Neurosci Biobehav Rev 28:143-180

Phillips RG, LeDoux JE (1992) Differential contribution of amygdala and hippocampus to cued and contextual fear conditioning. Behav Neurosci 106:274-285

Poldrack RA, Packard MG (2003) Competition among multiple memory systems: converging evidence from animal and human brain studies. Neuropsychologia 41:245-251

Ponnusamy R, Poulos AM, Fanselow MS (2007) Amygdala-dependent and amygdala-independent pathways for contextual fear conditioning. Neuroscience 174(4):919-927

Pope RE (1983) The Pre-outcome period and the utility of gambling. In: Stigum BP, Wenstøp F (eds) Foundations of utility and risk theory with applications, D. Reidel, Dordrecht, pp 37-177

Pope RE (1995) Towards a more precise decision framework, a separation of the negative utility of chance from diminishing marginal utility and the preference for safety. Theor Decis 39:241-265

Pope RE (2009) Risk starvation contributes to dementias and depressions: whiffs of danger are the antitode. Int J Psychol Couns 1:154-186

Rogan MT, Staubli UV, LeDoux JE (1997) Fear conditioning induces associative long-term potentiation in the amygdala. Nature 390:604-607 
Rosen JB, Donley MP (2006) Animal studies of amygdala function in fear and uncertainty: relevance to human research. Biol Psychol 73:49-60

Rothbaum BO, Davis M (2003) Applying learning principles to the treatment of post-trauma reactions. Ann NY Acad Sci 1008:112-121

Rothbaum BO, Schwartz AC (2002) Exposure therapy for posttraumatic stress disorder. Am J Psychother 56:59-75

Sah P, Westbrook F (2008) Behavioural neuroscience: the circuit of fear. Nature 454:589-590

Schneier FR, Neria Y, Pavlicova M, Hembree E, Suh EJ, Amsel L et al (2012) Combined prolonged exposure therapy and paroxetine for PTSD related to the World Trade Center attack: a randomized controlled trial. Am J Psychiatry 169:80-88

Shin LM, Liberzon I (2010) The neurocircuitry of fear, stress, and anxiety disorders. Neuropsychopharmacol 35:169-191

Slovic P, Peters E (2006) Risk perception and affect. Curr Dir Psychol 15:322-325

Sotres-Bayon F, Cain CK, LeDoux JE (2006) Brain mechanisms of fear extinction: historical perspectives on the contribution of prefrontal cortex. Biol Psychiatry 60:329-336

Sprengelmeyer R, Young AW, Schroeder U, Grossenbacher PG, Federlein J, Buttner T et al (1999) Knowing no fear. Proc Biol Sci 266:2451-2456

Stankowich T, Blumstein DT (2005) Fear in animals: a meta-analysis and review of risk assessment. Proc Biol Sci 272:2627-2634

Steinberg L (2007) Risk taking in adolescents: new perspectives from brain and behavior science. Curr Dir Psychol 16:55-59

Tom SM, Fox CR, Trepel C, Poldrack RA (2007) The neural basis of loss aversion in decision-making under risk. Science 315:515-518

Tranel D, Gullickson G, Koch M, Adolphs R (2006) Altered experience following bilateral amygdala damage. Cogn Neuropsychiatry 11:219-232 